\title{
Enhancing Gasoline Range Hydrocarbons by Catalytic Co-pyrolysis of Rice Husk with Low Density Polyethylene (LDPE) Using Zeolite Socony Mobil\#5(ZSM-5)
} \author{
Sumanth Raj Mogaveera ${ }^{1}$ \\ Department of Chemical Engineering, Siddaganga Institute of Technology, \\ Bengaluru - Honnavar Rd., 572103 Tumakuru, Karnataka, India \\ * Corresponding author, e-mail: binnalprakash@gmail.com
}

Prakash Binnal ${ }^{1 *}$, Vinayak Suresh Mali ${ }^{1}$, Shruthi Puttappa Karjekannavar ${ }^{1}$,

Received: 07 February 2019, Accepted: 22 May 2019, Published online: 15 August 2019

\begin{abstract}
In the present work, catalytic co-pyrolysis of rice husk with low density polyethylene (LDPE) was investigated to enhance the amount of gasoline range hydrocarbons in the bio-oil. Zeolite Socony Mobil\#5(ZSM-5) was used as catalyst. The specific surface area, pore volume and the average pore size of ZSM-5 were evaluated to be $418.041 \mathrm{~m}^{2} / \mathrm{g}, 0.227 \mathrm{cc} / \mathrm{g}$ and $1.628 \mathrm{~nm}$ respectively. Optimum temperature for obtaining highest bio-oil yield for non-catalytic co-pyrolysis was $600{ }^{\circ} \mathrm{C}$, resulting in yield of $51.26 \%$. For catalytic co-pyrolysis, the optimum temperature was $500{ }^{\circ} \mathrm{C}$ with a bio-oil yield of $38.87 \%$. H/C ratio of gasoline range hydrocarbon oil obtained by catalytic co-pyrolysis was 1.21, while the oxygen content was $2.51 \%$. The results of GC HRMS revealed that, the gasoline range hydrocarbon oil obtained by catalytic co-pyrolysis contained $17.65 \%$ Cycloalkanes, $6.131 \%$ alcohols, $31.75 \%$ esters and $32.68 \%$ alkenes.
\end{abstract}

Keywords

catalytic co-pyrolysis, LDPE, rice husk, ZSM-5

\section{Introduction}

Pyrolysis is regarded as promising technology for the production of bio-oils from biomass feedstock [1-6]. However, the bio-oils are viscous, highly oxygenated, acidic, chemically unstable, have higher water content and low H/C ratios [7]. Several techniques have been attempted to reduce the oxygen content of bio-oils. Among them, hydrodeoxygenation has been widely explored. However, this process suffers from several disadvantages such as requirement of high severity operating conditions (reaction temperature and hydrogen pressure), high operating cost related to noble catalysts used, catalyst deactivation etc. [8]. Alternatively, catalytic fast pyrolysis is one more attractive technique wherein the biomass is subjected to pyrolysis in the presence of acidic catalyst such as zeolites. This method offers advantages such as moderate pressure and temperatures requirement and does not require hydrogen. Further, it can produce several valuable petrochemicals (aromatics and olefins). However, carbon yield of aromatics is low (10-30\%) and large amounts of bio-char and coke are still produced which can be attributed to low H/C ratio of biomass, which ranges from 0 to 0.3 [9].
Co-pyrolysis is the most promising technique which can overcome the aforementioned limitations of other upgradation techniques of bio-oil. In Co-pyrolysis, biomass is co-fed with some hydrogen rich feedstocks such as waste plastics. Waste plastics are mainly formed by polymerization of olefins with high $\mathrm{H} / \mathrm{C}$ ratio of 2 , which indicates that they are suitable feedstocks for co-pyrolysis [10]. Furthermore, it was found that, the quality of bio-oil co-pyrolysis was higher than that from pyrolysis of biomass alone [11]. It was noticed that an increase in hydrogen content and decrease in oxygen content was observed in co-pyrolysis oil, resulting in an increased calorific value. Generally, the oxygenated organics that reduced the quality of bio-oil are aldehydes, ketones, phenols, esters etc. Co-pyrolysis is a simple and safe production process for high quality fuels since it does not bring in high-pressure hydrogenation. Hence the hydrogen transfer may also be involved in the co-pyrolysis under ambient pressure conditions. Also, huge amounts of waste plastics are globally generated. For instance, European Union (EU) exports out 3.4 million tons of 
waste plastic [12]. They have created several environmental problems and hence adequate disposal methods have to be designed. One alternative is to utilize them in co-pyrolysis along with biomass. Several researchers have reported that, a synergetic effect was observed between biomass and plastics during co-pyrolysis. Very recently, Uzoejinwa et al. [13] reviewed the various types of biomass and plastics used for co-pyrolysis and their efficiencies. However, to our best knowledge, there are no reports which describe the co-pyrolysis of rice husk with LDPE. In this regard, in the present work, we describe the co-pyrolysis of rice husk with LDPE. During production of rice, rice husk is generated as byproduct of milling factory and hence abundantly available to serve as a source of co-pyrolysis for current energy sector.

\section{Material and methods}

Rice husk (RH) was obtained from Sri Venkateshwara Rice Industries, Tumakuru, India and dried at $110{ }^{\circ} \mathrm{C}$ in a hot air oven for $24 \mathrm{~h}$. It was then ground to fine powder using domestic mixer and sieved to get an average size of $0.3 \mathrm{~mm}-0.6 \mathrm{~mm}$ size sample. LDPE was obtained from local market. N-Hexane, Methanol and ZSM-5 Zeolite catalyst (Si/Al ratio of 6) were procured from Sigma Aldrich.

\subsection{Fabrication of pyrolytic reactor}

A 5L capacity SS 304 lab scale pyrolytic reactor was used in present study. The schematic diagram of reactor is depicted in Fig. 1. The specifications of the reactor and furnace are given in Table 1. The nitrogen gas supply to the reactor was through a non-return valve. The gas outlet from reactor was connected to copper tube condenser (15 $\mathrm{m}$ long and $1 / 2$ inch diameter) through brazing and threaded joints. The copper coil was completely immersed in ice cooled chilled water (temperature: $4^{\circ} \mathrm{C}-5^{\circ} \mathrm{C}$ ). To the end of copper condenser, a gas collection bag was attached to collect non-condensable gases.

\subsection{Experimental procedure}

In all experiments, $100 \mathrm{~g}$ of feed was transferred to the reactor and heated to desired set temperature. The compositions of feedstock for co-pyrolysis were chosen as pure RH, pure LDPE and mixture of RH and LDPE in 1:1 ratio on weight basis. The average heating rate in the experiments was $17.5^{\circ} \mathrm{C} / \mathrm{min}$. After attaining the set temperature, pyrolysis was continued for known time and the biooil condensed in copper tube was removed by passing

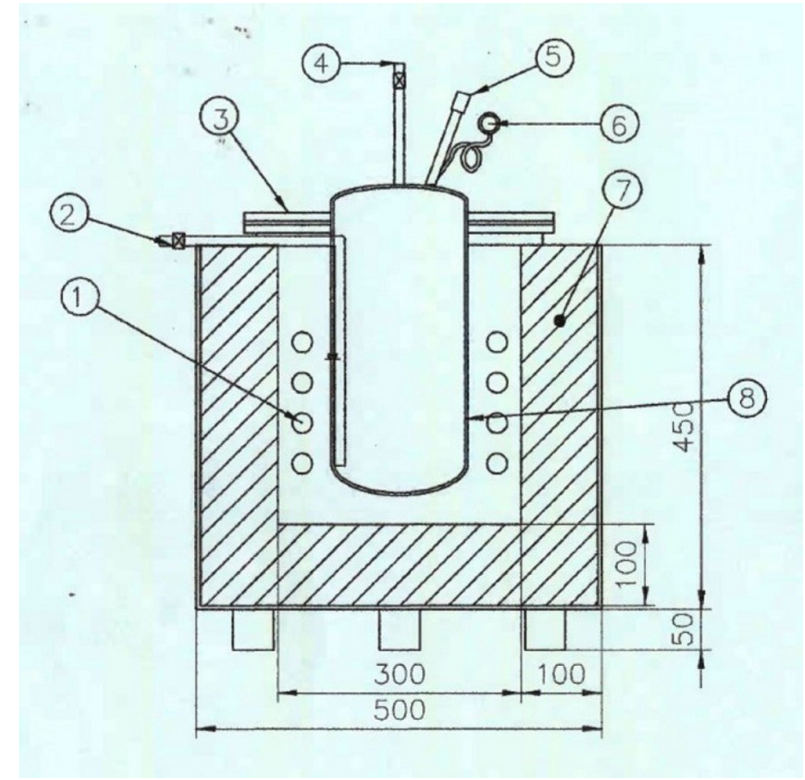

Fig. 1 Pyrolysis reactor (1-Heater, 2-Nitrogen inlet, 3-Flange, 4-Gas outlet, 5-Pressure relief valve, 6-Pressure gauge, 7-Thermal insulation, 8-Pyrolysis reactor)

Table 1 Specifications of pyrolysis reactor

\begin{tabular}{lcc}
\hline S.No & Component & Description \\
\hline 1. & Reactor & SS 304, $163 \mathrm{~mm} \mathrm{ID} \times 300 \mathrm{~mm}$ height \\
2. & $\begin{array}{c}\text { Maximum furnace } \\
\text { temperature }\end{array}$ & $800^{\circ} \mathrm{C}$ \\
& Power rating of & Kanthal A-1, $4.5 \mathrm{~kW}$ \\
3. & heater & 230 V Single phase 50 Hz AC \\
4. & Electric supply & Chromel Alumel (K-type) \\
5. & Thermocouple & PID \\
6. & Temperature control & Through steady state relay \\
7. & Power control &
\end{tabular}

compressed air. The mass of the waxy fuel obtained was measured. The mass of bio-char residue in reactor was also measured. The yield of bio-oil, bio-char and non-condensable was calculated as,

$Y_{B O}=($ Mass of biooil obatined $) /($ Mass of feed $) \times 100$

$Y_{B C}=($ Mass of biochar obatined $) /($ Mass of feed $) \times 100$

$Y_{N C}=($ Mass of gas obatined $) /($ Mass of feed $) \times 100$

where $Y_{B O}, Y_{B C}$ and $Y_{N C}$ refer to yields of bio-oil, bio-char and noncondensable gas respectively. Mass of non-condensable gases was obtained by mass balance as,

Mass of non-condensable gas

=100-Mass of biooil-Mass of biochar. 
The bio-oil obtained was subjected to simple distillation and a fraction with a boiling point range of room temperature to $204{ }^{\circ} \mathrm{C}$ was collected. This was called as "gasoline range hydrocarbon oil".

\subsection{Analytical methods}

\subsubsection{Composition of bio-oils by GC HRMS}

GC 7890 (Make: Agilent) with FID detector, along with Mass spectrometer: Jeol (Make: AccuTOF GCV) was used for GC HRMS analysis. The mass spectrometer had a range of 10-2000 amu and resolution of 6000 . A DB-5MS capillary column $(30 \mathrm{~m} \times 0.25 \mathrm{~mm} \times 0.25 \mathrm{~mm})$ was employed to separate components of the products. High-purity helium (99.999 \%) was used as the carried gas with a constant flow rate of $1.0 \mathrm{~mL} / \mathrm{min}$. The temperature of the injector was held at $280{ }^{\circ} \mathrm{C}$. The injection volume was $1 \mu \mathrm{L}$ (hexane was used as solvent). A split of the carrier gas (1:10) was used. The GC oven was programmed with the following temperature regime: hold at $80{ }^{\circ} \mathrm{C}$ for $1 \mathrm{~min}$, ramp to $200{ }^{\circ} \mathrm{C}$ at $8{ }^{\circ} \mathrm{C} / \mathrm{min}$, ramp to $275^{\circ} \mathrm{C}$ at $8{ }^{\circ} \mathrm{C} / \mathrm{min}$ and held at $275^{\circ} \mathrm{C}$ for $2 \mathrm{~min}$ and finally increased to $280{ }^{\circ} \mathrm{C}$ at rate of $5^{\circ} \mathrm{C} / \mathrm{min}$.

\subsubsection{Elemental analysis $(\mathrm{C}, \mathrm{H}, \mathrm{O})$}

FLASH EA 1112 series, Italy (Make: Thermo finnigan) was used for C-H-O-N analysis. 2-3 mg of sample in tin capsules was subjected to combustion at $900{ }^{\circ} \mathrm{C}$ and the resulting gases were separated by $\mathrm{GC}$ column and detected by TCD detector. Before analysis, the instrument was calibrated using L-Cystine as standard.

\subsubsection{BET Surface area of ZSM-5 catalyst}

Evaluation of specific surface area, pore volume and average pore size of ZSM-5 was done by Brunauer-EmmettTeller analysis (Quantachrome NOVA-1000, USA) using nitrogen adsorption - desorption isotherms at $77.4 \mathrm{~K}$.

\section{Results and discussions}

\subsection{BET Surface area of ZSM-5 catalyst}

The pore size distribution of ZSM-5 and adsorption-desorption isotherms of ZSM-5 are shown in Fig. 2 and Fig. 3 respectively. The specific surface area, pore volume and the average pore size were evaluated to be $418.041 \mathrm{~m}^{2} / \mathrm{g}$, $0.227 \mathrm{cc} / \mathrm{g}$ and $1.628 \mathrm{~nm}$ respectively. It was observed that, adsorption isotherm was of type II while desorption isotherm was of type VI.

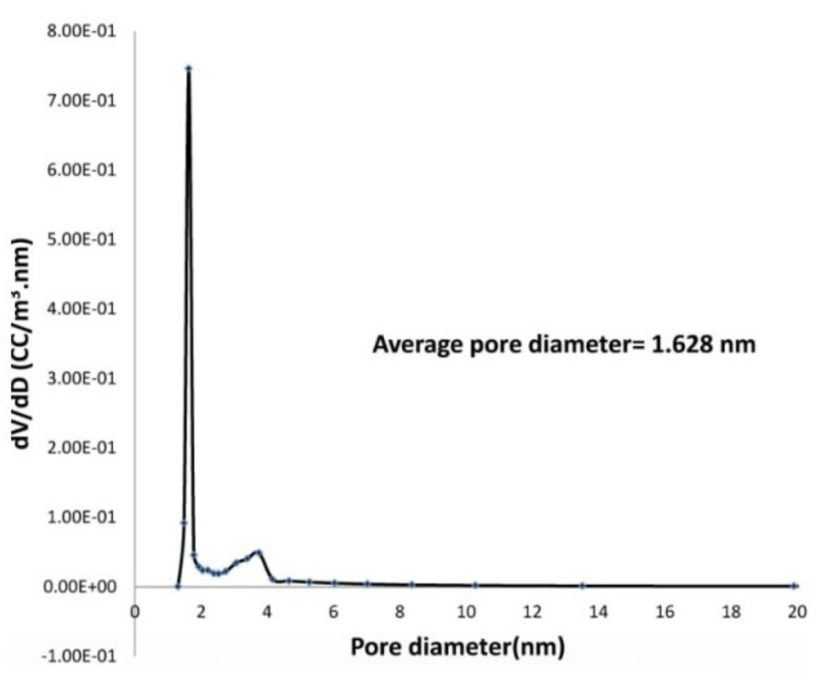

Fig. 2 Pore size distribution of catalyst ZSM-5 as measured by BET surfcae area

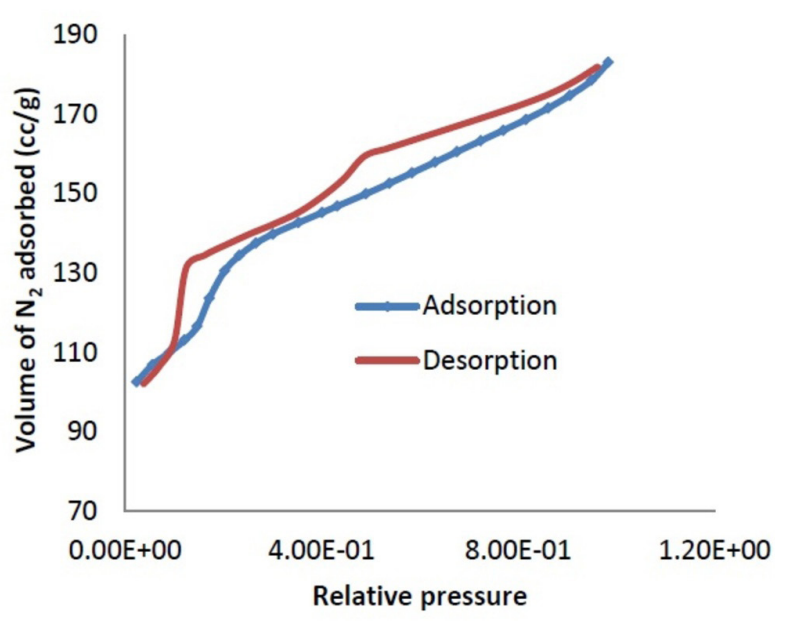

Fig. 3 Adsorption-desorption isotherms of ZSM-5 at 77.4 K, (Desorption-type VI and adsorption-type II)

\subsection{Effect of temperature on co-pyrolysis yields}

As one of the most important operating parameters in pyrolysis, temperature controls the cracking reaction of the feedstock and affects the pyrolysis product yields. The effect of temperature on the yields of bio-oil, noncondensable gases (NC) and bio-char for various feedstocks are depicted in Table 2. As can be observed, with increasing temperature, the yield of non-condensable gases continuously increased while the bio-char yield continuously decreased. With increase in temperature, bio-oil yield increases due to devolatization reactions [14].

However, at higher temperature, the vapour converts into smaller organic molecules or other non-condensable 
Table 2 Effect of temperature on pyrolysis yields (\%w/w)

\begin{tabular}{|c|c|c|c|c|c|c|}
\hline \multirow{2}{*}{ Feed stock } & \multicolumn{6}{|c|}{ Temperature $\left({ }^{\circ} \mathrm{C}\right)$} \\
\hline & \multirow{2}{*}{400} & \multirow{2}{*}{450} & \multirow{2}{*}{500} & \multirow{2}{*}{550} & \multicolumn{2}{|c|}{600} \\
\hline \multicolumn{3}{|l|}{ Rice husk } & & & & \\
\hline Bio-oil & \multirow[t]{3}{*}{15.23} & 19.46 & 24.56 & 22.51 & \multicolumn{2}{|c|}{20.17} \\
\hline Bio-char & & 51.21 & 42.65 & 36 & 33.24 & 31.58 \\
\hline Gas & & 33.56 & 37.89 & 39.44 & 44.25 & 48.25 \\
\hline \multicolumn{7}{|l|}{ LDPE } \\
\hline Bio-oil & & 85.45 & 87.49 & 87.71 & 85.26 & 81.52 \\
\hline Bio-char & & 5.2 & 1.11 & 0.40 & 0.26 & 0.84 \\
\hline Gas & & 9.35 & 11.41 & 11.89 & 14.48 & 17.64 \\
\hline \multicolumn{7}{|c|}{$\begin{array}{l}\text { Rice husk and } \\
\text { LDPE (1:1) }\end{array}$} \\
\hline Bio-oil & & 36.47 & 40.92 & 43.55 & 47.74 & 51.26 \\
\hline Bio-char & & 38.68 & 32.49 & 25.63 & 21.26 & 17.58 \\
\hline Gas & & 24.85 & 26.59 & 30.82 & 31.00 & 31.16 \\
\hline
\end{tabular}

gaseous products due to secondary cracking reactions. The char yield decreases with increasing temperature because of decomposition being promoted at higher temperature. The optimum temperature to obtain highest biooil yield was $500{ }^{\circ} \mathrm{C}$ for both $100 \%$ LDPE and $100 \%$ Rice husk samples, while for mixed feed of RH and LDPE (1:1), the optimum temperature was $600{ }^{\circ} \mathrm{C}$.

\subsection{Effect of feedstock composition on yields of products of co-pyrolysis}

As can be observed from Table 1, highest bio-oil yield for pure rice husk $24.56 \%(\mathrm{w} / \mathrm{w})$ at $500{ }^{\circ} \mathrm{C}$. With addition of LDPE in a ratio of 1:1, the bio-oil yield increased to $43.55 \%$ at same operating temperature. To compare the synergetic effect between rice husk and LDPE during co-pyrolysis, theoretical bio-yield $\left(Y_{T}\right)$ was calculated as,

$Y_{T}=\mathrm{Wt} \%$ of $\mathrm{RH} \times Y_{\mathrm{RH}}+\mathrm{Wt} \%$ of $\mathrm{LDPE} \times Y_{\mathrm{LDPE}}$

where, $Y_{\mathrm{RH}}$ and $Y_{\mathrm{LDPE}}$ represent experimental bio-oil yields of pure rice husk and LDPE respectively. According to Eq. (3), theoretical yield was for co-feed at $500{ }^{\circ} \mathrm{C}$ was $35.52 \%$ which was lower than experimental yield of $43.55 \%$. Similarly, a positive synergetic effect existed among at all temperatures between RH and LDPE. The experimental yield of bio-oil was higher than theoretical yield by $5.8 \%$, $7.96 \%, 11.65 \%, 22.60 \%$ and $12.67 \%$ at the temperatures $400{ }^{\circ} \mathrm{C}, 450{ }^{\circ} \mathrm{C}, 500{ }^{\circ} \mathrm{C}, 550{ }^{\circ} \mathrm{C}$ and $600{ }^{\circ} \mathrm{C}$ respectively. Further, it was found that, bio-char yield for pure $\mathrm{RH}$ decreased with addition of LDPE. This may be due to promotion of cracking of methoxy groups of phenols in $\mathrm{RH}$ bio-oil by hydrogen radicals provided by LDPE.

\subsection{Effect of temperature on catalytic co-pyrolysis}

Since the optimum temperature can differ for catalytic and non-catalytic co-pyrolysis, trials were conducted to optimize the temperature for catalytic co-pyrolysis. $2 \%$ ZSM-5 catalyst was used for these trials. As shown in Fig. 4, the optimum temperature for catalytic co-pyrolysis to obtain highest bio-yield was $500{ }^{\circ} \mathrm{C}$, which was lower than the corresponding value for non-catalytic runs $\left(600{ }^{\circ} \mathrm{C}\right)$. This result can be explained based on differences in the reaction mechanisms of catalytic and radicals disproportionation [11]. Herein, secondary radicals formation involves depolymerization, hydrogen transfer reactions, monomers formation, intermolecular hydrogen transfer (generation of paraffins and dienes) and isomerization through vinyl groups. While in catalytic co-pyrolysis, there will be interaction between pyrolytic intermediates at the active sites of catalyst. The primary reactions is between cellulose derived oxygenates and LDPE derived olefins at the active sites of acidic catalyst such as ZSM-5. Specifically, furans derived rice husk can react with light olefins such as ethylene and propylene from LDPE to form aromatic compounds. These aromatic compounds further undergo reactions such as hydrogenation, hydrocracking and hydroisomerization to form mono-cyclic alkanes [15]. Thus, since there are significant differences in the pathways of reactions occurring in catalytic and non-catalytic co-pyrolysis, the optimum temperature to obtain highest bio-oil can be different.

\subsection{Effect ZSM-5 concentration on yields of co-pyrolysis}

To understand the concentration of catalyst on yields of co-pyrolysis, experiments were conducted with varying concentrations of ZSM-5 in the range of $2 \%$ to $8 \%(\mathrm{w} / \mathrm{w})$ at $500{ }^{\circ} \mathrm{C}$. The results are presented in Fig. 5 .

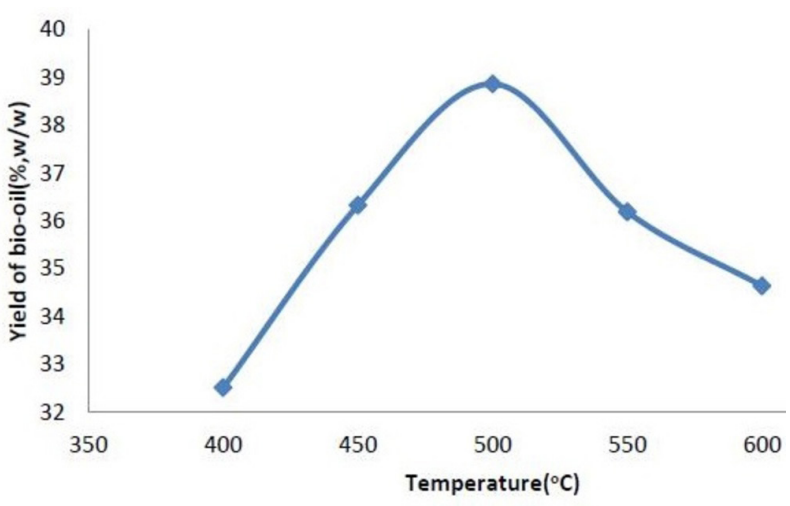

Fig. 4 Effect of temperature on yield of bio-oil during catalytic copyrolysis (Catalyst concentration $-2 \%$, RH:LDPE ratio $=1: 1$ ) 


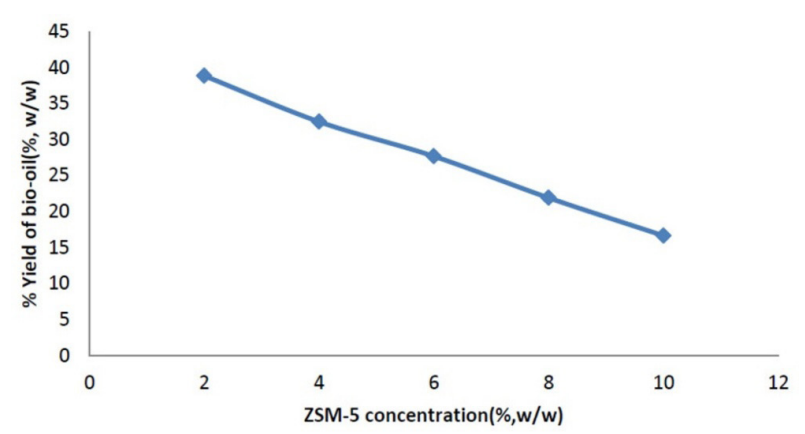

Fig. 5 Effect of concentration of ZSM-5 on yield of bio-oil $\left(\right.$ Temperature $-500{ }^{\circ} \mathrm{C}, \mathrm{RH}: \mathrm{LDPE}$ ratio $\left.=1: 1\right)$

The yield of bio-oil continuously decreased with increasing catalyst. This was evident because, in the presence of catalyst, reactions such as de-oxygenation will occur resulting in reduction of the mass of oil. The ZSM-5 has 3-D pore system containing straight ring channels connected by sinusoidal channels. In the present work, the range of pore size was $1.3031 \mathrm{~nm}$ to $38.2075 \mathrm{~nm}$. Hence, the oxygen containing pyrolytic intermediates, such as acids, ketones, and alcohols could be deoxygenated and cracked to $\mathrm{C}_{2}-\mathrm{C}_{6}$ olefins and alkanes in the pores of ZSM-5 [16]. Further, it has been known that, by changing $\mathrm{Si} / \mathrm{Al}$ ratio, it is possible to change the number of acid sites in ZSM-5. If the Si/Al ratio is low, higher amount of gases are formed due to high activity of $\mathrm{C}-\mathrm{C}$ bond scission [17]. In the present work, the ZSM-5 had $\mathrm{Si} / \mathrm{Al}$ ratio of 6 , which indicates the high acidity of catalyst. Hence, with increasing catalyst dosage, higher amount of gases were formed, resulting in lower yield of bio-oil. Table 3 shows the yield of gasoline range hydrocarbons at various catalyst concentrations. It is evident that, ZSM-5 concentration of $4 \%$ was optimum for obtaining highest yield of gasoline range hydrocarbons. Above this concentration, the yield of gaseous products was higher due to excessive cracking reactions, resulting in reduction of gasoline fraction.

Table 3 Effect of ZSM-5 concentration on yield of gasoline range fraction

\begin{tabular}{lcc}
\multicolumn{3}{c}{ gasoline range fraction } \\
\hline $\begin{array}{l}\text { Concentration of } \\
\text { catalyst }(\%, \mathrm{w} / \mathrm{w})\end{array}$ & $\begin{array}{c}\text { Yield of bio-oil } \\
(\%, \mathrm{w} / \mathrm{w})\end{array}$ & $\begin{array}{c}\text { Yield of gasoline } \\
\text { range fraction } \\
(\%, \mathrm{w} / \mathrm{w})\end{array}$ \\
\hline 2 & 38.87 & 12.69 \\
4 & 32.49 & 15.47 \\
6 & 27.69 & 14.21 \\
8 & 21.92 & 12.38 \\
10 & 16.66 & 10.12 \\
\hline *yield is based on weight of bio-oil &
\end{tabular}

*yield is based on weight of bio-oil

\subsection{Effect of ZSM-5 on $\mathrm{H} / \mathrm{C}$ ratio of bio-oils}

Table 4 depicts the elemental analysis and $\mathrm{H} / \mathrm{C}$ ratios of crude bio-oils obtained from various feed-stocks. It is evident that, non-catalytic co-pyrolysis was less efficient in reducing the oxygen content of crude rice husk bio-oil (from 13.54 to $12.08 \%$ ). Further/C ratio of bio-oil from (rice husk + LDPE) was slightly higher than the value for pure rice husk. On the other hand, catalytic co-pyrolysis with $4 \%$ ZSM-5 reduced the oxygen content of RH bio-oil to $2.65 \%$. Also, the $\mathrm{H} / \mathrm{C}$ ratio of bio-oil obtained from catalytic co-pyrolysis was higher than the value obtained from non-catalyzed co-pyrolysis (1.21 v/s 0.19). These results can be interpreted by the reaction mechanism of catalytic co-pyrolysis. The RH contains basically cellulose, hemicellulose and lignin. Cellulose undergoes reactions such as dehydration, decarbonylation and decarboxylation to generate furan compounds in the thermal degradation. Similarly, hemicellulose is also depolymerized into furan compounds. However, lignin is decomposed to phenolic compounds [18]. The degradation of LDPE occurs through random and chain end scission. In catalytic co-pyrolysis, the two reactions occur simultaneously in co-pyrolysis forming several free radicals together with long chain. At the same time, radical fragments will be transformed into straight chain hydrocarbons via "hydrogen transfer reactions" [19]. The hydrogen provided by thermal degradation of LDPE was accepted by biomass-derived oxygenates, thus reducing the biochar formation and increasing $\mathrm{H} / \mathrm{C}$ ratio.

\subsection{Effect of catalytic co-pyrolysis on composition of bio-oils}

The chemical compositions of bio-oil obtained from $\mathrm{RH}$, and gasoline range fractions obtained from LDPE, RH + LDPE (non-catalytic), RH + LDPE (catalytic, $4 \%$ ZSM-5) are depicted and compared in Table 5. As can be observed, biooils obtained from RH mostly consisted of phenols, furans,

Table 4 Elemental compositions of bio-oils obtained through different feedstocks

\begin{tabular}{lcccc}
\hline Feed for pyrolysis & $\mathrm{C}$ & $\mathrm{H}$ & $\mathrm{O}$ & $\mathrm{H} / \mathrm{C}$ \\
\hline $100 \%$ RH & 69.55 & 7.72 & 13.54 & 0.11 \\
$100 \%$ LDPE & 77.73 & 13.65 & 14.87 & 0.17 \\
$\begin{array}{l}\text { RH + LDPE (1:1) } \\
\text { without catalyst }\end{array}$ & 82.13 & 15.60 & 12.08 & 0.19 \\
$\begin{array}{l}\text { RH + LDPE (1:1) } \\
\text { with 4 \% ZSM-5 }\end{array}$ & 64.17 & 77.65 & 2.65 & 1.21 \\
\hline
\end{tabular}


Table 5 Comparison of composition of rice husk bio-oil with gasoline range hydrocarbon oils obtained by co-pyrolysis

\begin{tabular}{|c|c|c|c|c|}
\hline Class of compounds & $\begin{array}{l}\text { Bio-oil from } \\
\text { Rice husk }\end{array}$ & $\begin{array}{c}\text { Gasoline range } \\
\text { hydrocarbon oil } \\
\text { from } 100 \% \mathrm{LDPE}\end{array}$ & $\begin{array}{c}\text { Gasoline range } \\
\text { hydrocarbon oil } \\
\text { from 1:1 feed of LDPE } \\
\text { and RH (Uncatalyzed) }\end{array}$ & $\begin{array}{l}\text { Gasoline range } \\
\text { hydrocarbon oil } \\
\text { from 1:1 feed of LDPE } \\
\text { and RH (Catalyzed) }\end{array}$ \\
\hline \multicolumn{5}{|l|}{ Ketones } \\
\hline Ethanone,1-(2-methyl-1cyclopenten-1-yl)- & 4.14 & - & - & - \\
\hline 2-Piperidinone,N-[4-bromo-n-butyl]- & 18.71 & - & - & - \\
\hline \multicolumn{5}{|l|}{ Silanes } \\
\hline $\begin{array}{l}\text { Silane.dimethyl(dimethyl(2-bromo-4fluorophenoxy) } \\
\text { silyloxy)(2-bromo-4-fluorophenoxy)- }\end{array}$ & 8.31 & - & - & - \\
\hline \multicolumn{5}{|l|}{ Furans } \\
\hline 3-methyl-2-(2-oxopropyl)Furan & 5.9 & - & - & - \\
\hline \multicolumn{5}{|l|}{ Phenol } \\
\hline Phenol,4-ethyl- & 5.74 & - & - & - \\
\hline \multicolumn{5}{|l|}{ Esters } \\
\hline Hexatriacontyl penta fluoropropionate & 12.25 & - & - & - \\
\hline Phthalic acid,decyl 7-methyl oct-3yn-5-yl Ester & 1.41 & - & - & - \\
\hline Nitric acid,nonyl Ester & 9.65 & - & - & - \\
\hline Oxalic acid, allyl pentadcyl Ester & 19.36 & - & - & - \\
\hline Nitric acid,nonyl Ester & 14.51 & - & - & - \\
\hline Oxalic acid,allyl hexadecyl Ester & & 0.75 & - & - \\
\hline $\begin{array}{l}\text { 1,2-Benzenedicarboxylic acid,bis(2-methylpropyl) } \\
\text { Ester }\end{array}$ & & 0.79 & - & - \\
\hline Oxalic acid,allyl hexadecyl Ester & & 2.43 & - & - \\
\hline Oxalic acid,allyl hexadecyl Ester & & 1.84 & - & - \\
\hline Oxalic acid,allyl hexadecyl Ester & & 1.29 & - & - \\
\hline Sulfurous acid,octadecyl 2-pentyl Ester & & 1.09 & - & - \\
\hline Oxalic acid,allyl hexadecyl Ester & & 1.01 & - & - \\
\hline Oxalic acid,allyl octadecyl Ester & & 0.85 & - & - \\
\hline Oxalic acid,allyl hexadecyl Ester & & 0.77 & - & - \\
\hline Oxalic acid,allyl hexadecyl Ester & - & - & 7.79 & - \\
\hline Decyl trifluoroacetate & - & - & 1.56 & - \\
\hline Acetic acid,trifluoro,2,2-dimethylpropyl Ester & - & - & 0.57 & - \\
\hline Nitric acid,nonyl Ester & - & - & 0.48 & - \\
\hline Oxalic acid,allyl nonyl Ester & - & - & 2.03 & - \\
\hline Oxalic aicd,allyl nonyl Ester & - & - & 0.9 & - \\
\hline Oxalic acid, allyl hexadecyl Ester & - & - & 1.89 & - \\
\hline Oxalic acid, allyl hexadecyl Ester & - & - & 0.4 & - \\
\hline Oxalic aicd,allyl pentadecyl Ester & - & - & 2.69 & - \\
\hline Oxalic aicd,allyl pentadecyl Ester & - & - & 1.76 & - \\
\hline Sulfurous acid, hexyl pentadecyl Ester & - & - & - & 1.6 \\
\hline Sulfurous acid, hexyl pentadecyl Ester & - & - & - & 2.31 \\
\hline Oxalic acid, allyl octadecyl Ester & - & - & - & 5.75 \\
\hline $\begin{array}{l}\text { 9-Octadecenoic acid (Z)-, 2-(acetyloxy)-1- } \\
\text { [(acetyloxy)methyl] ethyl Ester }\end{array}$ & - & - & - & 2.63 \\
\hline Oxalic acid, allyl octadecyl Ester & - & - & - & 7.02 \\
\hline Oxalic acid, allyl dodecyl Ester & - & - & - & 2.15 \\
\hline
\end{tabular}




\begin{tabular}{|c|c|c|c|c|}
\hline Class of compounds & $\begin{array}{l}\text { Bio-oil from } \\
\text { Rice husk }\end{array}$ & $\begin{array}{l}\text { Gasoline range } \\
\text { hydrocarbon oil } \\
\text { from } 100 \% \text { LDPE }\end{array}$ & $\begin{array}{c}\text { Gasoline range } \\
\text { hydrocarbon oil } \\
\text { from 1:1 feed of LDPE } \\
\text { and RH (Uncatalyzed) }\end{array}$ & $\begin{array}{c}\text { Gasoline range } \\
\text { hydrocarbon oil } \\
\text { from 1:1 feed of LDPE } \\
\text { and RH (Catalyzed) }\end{array}$ \\
\hline \multicolumn{5}{|l|}{ Alkenes } \\
\hline 1-Decene & - & 15.3 & - & - \\
\hline 7-Hexadecene,(Z)- & - & 4.82 & - & - \\
\hline 5-Octadecene,[E]- & - & 3.65 & - & - \\
\hline 7-Hexadecene,(Z)- & - & 3.11 & - & - \\
\hline 3-Tetradecene, $(Z)-$ & - & 8.01 & - & - \\
\hline 1-Tetradecene & - & 12.04 & - & - \\
\hline 5-Ethyl-1-nonene & - & - & 5.71 & - \\
\hline 1-Undecene & - & - & 15.75 & - \\
\hline 1-4-Heptadiene-3,3,6-trimethyl- & - & - & 1.14 & - \\
\hline 1-Octene,3,7-dimethyl- & - & - & 7.92 & - \\
\hline 2-Dodecene,€- & - & - & 5.12 & - \\
\hline 3-Tetradecene,(Z)- & - & - & 5.01 & - \\
\hline 7-Tetradecene, (Z)- & - & - & - & 10.18 \\
\hline 1-Hexadecene & - & - & - & 6.88 \\
\hline 5-Octadecene, (E)- & - & - & - & 4.34 \\
\hline 3-Octadecene, (E)- & - & - & - & 3.54 \\
\hline 1-Tridecene & - & - & - & 6.06 \\
\hline \multicolumn{5}{|l|}{ Alkanes } \\
\hline 1-Iodo-2-methyl undecane & - & 1.45 & - & - \\
\hline 1-Pentadecane & - & 6.12 & - & - \\
\hline Undecane & - & 7.84 & - & - \\
\hline 3-Dodecane & - & 15.37 & - & - \\
\hline Undecane & - & - & 5.24 & - \\
\hline Octane,3,4,5,6-tetramethyl- & - & - & 0.91 & - \\
\hline Tetradecane,1-chloro- & - & - & 0.66 & - \\
\hline Tetratetracontane & - & - & 2.1 & - \\
\hline 1-Iodo-2-methylundecane & - & - & - & 1.33 \\
\hline Tetracontane, 3,5,24-trimethyl & - & - & - & 8.74 \\
\hline \multicolumn{5}{|l|}{ Cycloalkanes } \\
\hline Cyclopropane,1-heptyl-2-methyl- & - & 8.54 & - & - \\
\hline Cyclopropane, 1-heptyl-2-methyl & - & - & - & 8.68 \\
\hline Cyclopropane, 1-methyl-2-octyl & & - & - & 8.97 \\
\hline \multicolumn{5}{|l|}{ Alcohols } \\
\hline 1,14-Tetradecanediol & - & 2.95 & - & - \\
\hline 2-Butyn-1-ol-4-methoxy- & - & - & 0.76 & - \\
\hline$[2,4,6$-Trimethylcyclohexyl]methanol & - & - & - & 0.79 \\
\hline 1-Octanol, 2-butyl & - & - & - & 1.44 \\
\hline
\end{tabular}

acids and esters. No alkene / alkane / cycloalkanes were observed. Among the ketones, 2-Piperidinone, N-[4-bromon-butyl]-was present in highest concentration (18.71\%). On the other hand, the hydrocarbon oil obtained from $100 \%$ LDPE consisted of mainly alkenes ( $46.92 \%$ ), alkanes $(30.78 \%)$, cycloalkanes $(8.5 \%)$ and small amounts of alcohols (2.94\%). The major alkene was 1-Tetradecene (12.04\%), while the major alkane was 3-Dodecane (15.37\%).
In the case of co-feed (50\% RH $+50 \%$ LDPE, Un-catalyzed), no cycloalkanes were observed and the biooil primarily consisted of esters (45.16\%) and alkenes (45.178 \%). Among esters, oxalic acid-allyl hexadecyl ester was major component, while, 1-Undecene was the dominant alkene (15.75\%). The concentration of alkanes was lower as compared to $100 \%$ LDPE (8.91\%). The gasoline range hydrocarbon oil from co-feed (50\% RH + $50 \%$ LDPE, $4 \%$ 
ZSM-5) was found to contain primarily esters and alkenes (31.75 \% and $32.68 \%$ respectively). However, the concentrations of cycloalkanes was almost twice than the value for $100 \%$ LDPE (17.65 \%).

The formation of Cyclohexanes can be explained by referring to reaction mechanisms of catalytic co-pyrolysis. As explained in Section 3.6, hydrogen obtained from thermal degradation of LDPE and furans obtained from $\mathrm{RH}$ react through Diels-Alder reaction to form aromatic compounds. Apart from this, the olefins from LDPE can individually undergo cyclization, aromatization, decarbonylation, and oligomerization inside the pores of ZSM-5 to form aromatic compounds [20]. Basically, the primary vapors will diffuse into the internal pores of ZSM-5 when passing through catalyst layer, and form aromatic hydrocarbons through a common hydrocarbon pool intermediate. In addition, phenolic compounds produced from RH undergo dehydration, cracking and oligomerization to form aromatics. These aromatics can undergo hydro cyclo-addition process to form Cycloalkanes. Cycloalkanes are desired components in gasoline. A higher concentration of them suggested that the fuel obtained was of better quality than the other oils. Moreover, a higher concentration of alcohols (6.131\%) suggested that the oil was rich in high energy compounds. Further, the hydrocarbon oil obtained from catalytic co-pyrolysis showed the absence of oxygen containing compounds like furans, phenols, ketones (which were the primary compounds). Thus, catalytic co-pyrolysis could decrease the oxygen content of bio-oil.

A comparison of concentrations of various chemical groups in rice husk bio-oil with those obtained by co-pyrolysis is depicted in Table 6.

\section{Conclusions}

The present work showed that, catalytic co-pyrolysis of RH with LDPE using ZSM-5 significantly improved the quality of bio-oil of rice husk bio-oil. However, a reduction in yield was observed as compared to non-catalytic co-pyrolysis (38.87\% v/s $51.26 \%$ ). The optimum composition of feedstock was evaluated as 1:1 ratio of $\mathrm{RH}$ and LDPE. The optimum temperature for non-catalytic
Table 6 Comparison of compositions of bio-oils

\begin{tabular}{|c|c|c|c|c|}
\hline \multirow[b]{2}{*}{ lassification } & \multirow[b]{2}{*}{$\begin{array}{c}\text { RH } \\
\text { bio-oil }\end{array}$} & \multicolumn{3}{|c|}{$\begin{array}{l}\text { Gasoline range hydrocarbon oil } \\
\text { obtained from: }\end{array}$} \\
\hline & & $\begin{array}{l}100 \% \\
\text { LDPE }\end{array}$ & $\begin{array}{c}50 \% \text { RH and } \\
50 \% \text { LDPE } \\
\text { (Uncatalyzed) }\end{array}$ & $\begin{array}{c}50 \% \text { RH and } \\
50 \% \text { LDPE } \\
\text { (Catalyzed, } \\
4 \% \text { ZSM-5) }\end{array}$ \\
\hline Ketones & 22.85 & - & - & - \\
\hline Silanes & 8.311 & - & - & - \\
\hline Furans & 5.903 & - & - & - \\
\hline Phenols & 5.743 & - & - & - \\
\hline Esters & 57.18 & - & 45.160 & 31.758 \\
\hline Alkenes & - & 46.922 & 45.178 & 32.685 \\
\hline Alkanes & - & 30.777 & 8.9059 & 11.773 \\
\hline Cycloalkanes & - & 8.539 & - & 17.65 \\
\hline Alcohols & - & 2.945 & 0.7553 & 6.131 \\
\hline
\end{tabular}

and catalytic pyrolysis was $600{ }^{\circ} \mathrm{C}$ and $500{ }^{\circ} \mathrm{C}$ respectively, which indicates that, the energy requirements of pyrolysis are reduced in the presence of ZSM-5. The optimum catalyst dosage was $4 \mathrm{wt} \%$. The oxygen content reduced $13.54 \%$ for $\mathrm{RH}$ bio-oil to $2.51 \%$ when ZSM-5 was used along with LDPE. The $\mathrm{H} / \mathrm{C}$ ratio increased from 0.17 to 1.21 . An analysis of chemical compositions of biooils showed that, the bio-oil from RH mostly consisted of furans, acids and esters while the one obtained from catalytic co-pyrolysis with LDPE consisted of significant quantities of cycloalkanes, alcohols, alkenes and esters, which confirmed that there were significant interactions existed between pyrolysis intermediates of RH and LDPE resulting in the improvement of quality of bio-oil.

\section{Acknowledgement}

The authors gratefully thank the financial assistance from Sree Siddaganga Education Society, Tumakuru and BRC, IIChE, Bangalore (under IIChE, BRC project grant).

\section{Nomenclature}

$\begin{array}{ll}\text { LDPE } & \text { Low Density Polyethylene } \\ \text { RH } & \text { Rice husk } \\ Y_{T} & \text { Theoretical bio-oil yield } \\ Y_{\text {RH }} & \text { Yield of bio-oil from Rice husk(Experimental) } \\ Y_{\text {LDPE }} & \text { Yield of bio-oil from LDPE (Experimental) }\end{array}$




\section{References}

[1] Vlaev, L. T., Markovska, I. G., Lyubchev, L. A. "Non-isothermal kinetics of pyrolysis of rice husk", Thermochimica Acta, 406(1-2), pp. 1-7, 2003.

https://doi.org/10.1016/S0040-6031(03)00222-3

[2] Quispe, I., Navia, R., Kahhat, R. "Energy potential from rice husk through direct combustion and fast pyrolysis: A review", Waste Management, 59, pp. 200-210, 2017.

https://doi.org/10.1016/j.wasman.2016.10.001

[3] Alvarez, J., Lopez, G., Amutio, M., Bilbao, J., Olazar, M. "Bio-oil production from rice husk fast pyrolysis in a conical spouted bed reactor", Fuel, 128, pp. 162-169, 2014.

https://doi.org/10.1016/j.fuel.2014.02.074

[4] Mohammed, I. Y., Lim, C. H., Kazi, F. K., Yusup, S., Lam, H. L., Abakr, Y. A. "Co-pyrolysis of Rice Husk with Underutilized Biomass Species: A Sustainable Route for Production of Precursors for Fuels and Valuable Chemicals", Waste and Biomass Valorization, 8(3), pp. 911-921, 2017. https://doi.org/10.1007/s12649-016-9599-9

[5] Lin, B., Huang, Q., Chi, Y. "Co-pyrolysis of oily sludge and rice husk for improving pyrolysis oil quality", Fuel Processing Technology, 177, pp. 275-282, 2018. https://doi.org/10.1016/j.fuproc.2018.05.002

[6] Naqvi, S. R., Hameed, Z., Tariq, R., Taqvi, S. A., Ali, I., Niazi, M. B. K., Noor, T., Hussain, A., Iqbal, N., Shahbaz, M. "Synergistic effect on co-pyrolysis of rice husk and sewage sludge by thermal behaviour, kinetics, thermodynamic parameters and artificial neural network", Waste Management, 85, pp. 131-140, 2019. https://doi.org/10.1016/j.wasman.2018.12.031

[7] Qi, Z., Jie, C., Tiejun, W., Ying, X. "Review of biomass pyrolysis oil properties and upgrading research", Energy Conversion and Management, 48(1), pp. 87-92, 2007.

https://doi.org/10.1016/j.enconman.2006.05.010

[8] Parihar, M. F., Kamil, M., Goyal, H. B., Gupta, A. K., Bhatnagar, A. K. "An experimental study on pyrolysis of biomass", Process Safety and Environmental Protection", 85(5), pp. 458-465, 2007. https://doi.org/10.1205/psep07035

[9] Li, X., Zhang, H., Li, J., Su, L., Zuo, J., Komarneni, S., Wang, Y. "Improving the aromatic production in catalytic fast pyrolysis of cellulose by co-feeding low-density polyethylene", Applied Catalysis A: General, 455, pp. 114-121, 2013. https://doi.org/10.1016/j.apcata.2013.01.038

[10] Zhang, H., Nie, J., Xiao, R., Jin, B., Dong, C., Xiao, G. "Catalytic co-pyrolysis of biomass and different plastics (polyethylene, polypropylene, and polystyrene) to improve hydrocarbon yield in a fluidized-bed reactor", Energy \& Fuels, 28(3), pp.1940-1947, 2014. https://oi.org/10.1021/ef4019299
[11] Önal, E., Uzun, B. B., Pütün, A. E., "Bio-oil production via co-pyrolysis of almond shell as biomass and high density polyethylene", Energy Conversion and Management, 78, pp. 704-710, 2014. https://doi.org/10.1016/j.enconman.2013.11.022

[12] Ongondo, F. O., Williams, I. D., Cherrett, T. J. "How are WEEE doing? A global review of the management of electrical and electronic wastes", Waste Management, 31(4), pp. 714-730, 2014. https://doi.org/10.1016/j.wasman.2010.10.023

[13] Uzoejinwa, B. B., He, X., Wang, S., Abomohra, A. E.-F., Hu, Y., Wang, Q. "Co-pyrolysis of biomass and waste plastics as a thermochemical conversion technology for high-grade biofuel production: Recent progress and future directions elsewhere worldwide", Energy Conversion and Management, 163, pp. 468-492, 2018. https://doi.org/10.1016/j.enconman.2018.02.004

[14] Zhou, L., Yang, H., Wu, H., Wang, M., Cheng, D. "Catalytic pyrolysis of rice husk by mixing with zinc oxide: characterization of bio-oil and its rheological behavior", Fuel Processing Technology, 106, pp. 385-391, 2013.

https://doi.org/10.1016/j.fuproc.2012.09.003

[15] Li, X., Zhang, H., Li, J., Su, L., Zuo, J., Komarneni, S., Wang, Y. "Improving the aromatic production in catalytic fasct pyrolysis by co-feeding low-density polyethylene", Applied Catalysis A: General, 455, pp. 114-121, 2013. https://doi.org/10.1016/j.apcata.2013.01.038

[16] Xie, Q., Addy, M., Liu, S., Zhang, B., Cheng, Y., Wan, Y., Li, Y., Liu, Y., Lin., X., Chen, P., Ruan, R. "Fast microwave catalytic co-pyrolysis of microalgae and scum for bio-oil production", Fuel, 16, pp. 577-582, 2015. https://doi.org/10.1016/j.fuel.2015.08.020

[17] Ratnasari, D. K., Nahil, M. A., Williams, P. T. "Catalytic pyrolysis of waste plastics using staged catalysis for production of gasoline range hydrocarbon oils", Journal of Analytical and Applied Pyrolysis, 124, pp. 631-637, 2017. https://doi.org/10.1016/j.jaap.2016.12.027

[18] Miao, X., Wu, Q., Yang, C. "Fast pyrolysis of microalgae to produce renewable fuels", Journal of Anayltical and Applied Pyrolysis, 71(2), pp. 855-863, 2004.

https://doi.org/10.1016/j.jaap.2003.11.004

[19] Yu, G., Zhang, Y., Schideman, L., Funk, T. L., Wang, Z. "Hydrothermal liquefaction of low lipid content microalgae into bio-crude oil", 54(1), pp. 239-246, 2011. https://doi.org/10.13031/2013.36241

[20] Xue, Y., Kelkar, A., Bai, X. "Catalytic co-pyrolysis of biomass and polyethylene in a tandem micropyrolyzer", Fuel, 166, pp. 227-236, 2016. https://doi.org/10.1016/j.fuel.2015.10.125 